\title{
Improved Stability and Shape Selectivity of 2,6-Dimethylnaphthalene by Methylation of Naphthalene with Methanol on Modified Zeolites
}

\author{
Ye Zhang*, Junpeng Feng, Zhanjun Lyu, Xuekuan Li* \\ Institute of Coal Chemistry, Chinese Academy of Sciences, Taiyuan, China \\ Email: *yzhang@sxicc.ac.cn
}

Received 27 December 2013; revised 27 January 2014; accepted 5 February 2014

Copyright (C) 2014 by authors and Scientific Research Publishing Inc.

This work is licensed under the Creative Commons Attribution International License (CC BY). http://creativecommons.org/licenses/by/4.0/

(c) (i) Open Access

\begin{abstract}
2,6-Dimethylnaphthalene (2,6-DMN) is a key intermediate for polyethylene naphthalate synthesis. The selective synthesis of 2,6-DMN from naphthalene and methanol was carried out over different zeolites (HZSM-5, H $\beta$, HUSY and SAPO-11) modified by $0.1 \mathrm{wt} \%$ PdO under atmospheric pressure. Among the adopted zeolites, SAPO-11 exhibits exceptional shape-selectivity and stability to synthesize 2,6-dimethylnaphthalene from methylation of naphthalene, due to the special pore structure of SAPO-11 which inosculated better with 2,6-dimethylnaphthalene than with 2,7-dimethylnaphthalene.
\end{abstract}

Keywords

Naphthalene Methylation; 2,6-Dimethylnaphthalene; Shape-Selective; Stability; PdO Modified Zeolites

\section{Introduction}

Polyethylene naphthalate (PEN) is widely used as a functional polymer because of its superior thermal and chemical stability, gas barrier and mechanical properties [1]-[3]. PEN can be synthesized via polymerization of 2,6-naphthalene dicarboxylic acid monomer which is derived from a rather expensive intermediate, 2,6-dimethylnaphthalene (2,6-DMN) [1]. BP-Amoco developed a 4-step strategy to synthesize 2,6-DMN using o-xylene and butadiene as the starting agents, which is environmentally harmful, costly and complicated [2]. Recently,

\footnotetext{
*Corresponding authors.
}

How to cite this paper: Zhang, Y., et al. (2014) Improved Stability and Shape Selectivity of 2,6-Dimethylnaphthalene by Methylation of Naphthalene with Methanol on Modified Zeolites. Modern Research in Catalysis, 3, $19-25$. 
catalytic methylation with naphthalene and methanol to 2,6-DMN has been proposed as a single-pot and environmentally benign alternative to the BP-Amoco process [4]-[7]. Dimethylnaphthalenes have 10 isomers with very similar boiling points. Therefore, it is difficult to purify 2,6-DMN in a unselective naphthalene methylation reaction. Therefore, developing a single-pot, high-yield and selective route for the preparation of 2,6-DMN remains an extremely challenging and elusive goal, and one in which the zeolite catalysts may play a crucial role.

Zeolites are environmentally friendly catalysts with controllable porous structures and surface acidity. When appropriately selected, these tunable properties can provide improved selectivity for desired product phases. Recently, a variety of zeolitic catalysts, mainly ZSM-5, ZSM-11, ZSM-12, MCM-22 and $\beta$, M, Y aluminosilicate zeolites, have been utilised as catalysts in the naphthalene methylation reaction [3]-[7]. In these attempts on the naphthalene methylation, the reported highest selectivity of 2,6-DMN reached 29\% under 4 MPa system pressure. These catalysts, however, are not suitable for industrial applications due to the low product selectivity and high operation pressures required [8]. The discovery of efficient catalysts that operate under mild conditions is highly desired to realize the practical production of 2,6-DMN via naphthalene methylation.

The microporous SAPO- 11 silicoaluminophosphate zeolite consists of non-intersecting elliptical 10-memberring pores (Table 1) of $0.39 \mathrm{~nm} \times 0.64 \mathrm{~nm}$ in dimension and has an AEL topology [9]. SAPO-11 has previously been utilized for the selective hydroisomerization of n-octane [10] and n-decane [11]. In our previous work, HZSM-5, H $\beta$, HUSY and SAPO-11 were used as catalysts for the synthesis of 2,6-DMN [12] and SAPO-11 showed high selectivity for 2,6-DMN. But the stability was very poor and most of the activity lost after four hours reaction. Here, we modified the zeolites with $0.1 \mathrm{wt} \%$ PdO to improve the stability of SAPO- 11 and other zeolites for the synthesis of 2,6-DMN via naphthalene-methanol methylation. In particular, PdO/SAPO-11 is found to be highly selective and stable in naphthalene-methanol methylation reaction under mild atmospheric pressure. The superior shape selectivity of SAPO-11was discussed in-depth.

\section{Experimental}

\subsection{Materials and Reaction}

HZSM-5, H $\beta$ and HUSY were received from Nankai Catalysts Co., and SAPO-11 from Tianjin Chemist Catalyst Corpration. The modification was carried out by dip the zeolites powder in acidic $\mathrm{Pd}\left(\mathrm{NO}_{3}\right)_{2}$ solution by isometric impregnation method. The as-prepared catalysts were then dried at $100^{\circ} \mathrm{C}$ followed by calcination at $500^{\circ} \mathrm{C}$ for $4 \mathrm{~h}$ to obtain the catalyst with $1 \mathrm{wt} \% \mathrm{PdO}$ loading amount. In the evaluation experiments under ambient pressure, the reactant mixture of naphthalene, methanol and trimethlybenzene were injected by a highpressure pump into a tubular fixed-bed stainless-steel reactor. $2 \mathrm{~g}$ of catalyst pellets with the size of $20 \sim 40$ mesh were put in the constant temperature zone, and its up \& down sides covered with quartz sands of $20 \sim 40$ mesh. Prior to reaction, the catalyst was pretreated in $\mathrm{N}_{2}$ flow at $540^{\circ} \mathrm{C}$ for $2 \mathrm{~h}$ then cooled to $350^{\circ} \mathrm{C}$. The typical reaction parameters are as follows: atmospheric pressure, reaction temperature of $350^{\circ} \mathrm{C}, 0.24 \mathrm{~h}^{-1}$ weight hourly space velocity (WHSV, calculated as naphthalene feed), and the 1,2,4-trimethlybenzene : naphthalene:methanol molar ratio (in liquid feed) of 3.5:1:5. The products were analyzed by GC with a Beta-DEX-120 capilary column $(60 \mathrm{~m} \times 0.25 \mathrm{~mm} \times 0.25 \mu \mathrm{m})$. The typical analysis conditions were as follows: constant temperature of $160^{\circ} \mathrm{C}$ for $36 \mathrm{~min}$; temperature was increased to $190^{\circ} \mathrm{C}$ at a ramping rate of $10^{\circ} \mathrm{C} / \mathrm{min}$ and remained constant for $45 \mathrm{~min}$. Nitrogen was used as the carrier gas. Injection and FID detector temperature was set at $300^{\circ} \mathrm{C}$. The conversion of naphthalene was calculated through (MNAPHO-MNAPH)/MNAPHO $\times 100 \%$, where MNAPHO and MNAPH denoted the molar fraction of naphthalene before and after reaction, respectively. The selectivity of

Table 1. The topology and pore structures of the selected zeolites.

\begin{tabular}{|c|c|c|c|}
\hline Zeolite & Topology & Pore Channel & Pore Opening (nm) \\
\hline SAPO-11 & AEL & Unidimensional & 10-MRa: $0.39 \times 0.64\left(\begin{array}{lll}0 & 0 & 1\end{array}\right)$ \\
\hline $\mathrm{H} \beta$ & BEA & Tridimensional & $\begin{array}{l}\text { 12-MR: } 0.66 \times 0.77\left(\begin{array}{lll}1 & 0 & 0\end{array}\right) \\
12-M R: 0.56 \times 0.56\left(\begin{array}{lll}0 & 0 & 1\end{array}\right)\end{array}$ \\
\hline HUSY & FAU & Tridimensional supercage & 12-MR: $0.74 \times 0.74\left(\begin{array}{lll}1 & 1 & 1\end{array}\right)$ \\
\hline HZSM-5 & MFI & Bidimensional intersection & $\begin{array}{l}\text { 10-MR: } 0.51 \times 0.54\left(\begin{array}{lll}1 & 0 & 0\end{array}\right) \\
\text { 10-MR: } 0.54 \times 0.56\left(\begin{array}{lll}0 & 1 & 0\end{array}\right)\end{array}$ \\
\hline
\end{tabular}


2,6-DMN $\left(\mathrm{S}_{2,6-\mathrm{DMN}}\right)$ was considered as the molar percentage of 2,6-DMN out of the total amount of substituted naphthalene.

\subsection{Characterizations}

Temperature-programmed desorption of ammonia $\left(\mathrm{NH}_{3}-\mathrm{TPD}\right)$ was measured on a self-designed apparatus equipped with a TC detector. Typically, $0.2 \mathrm{~g}$ sample was first pretreated in flowing $\mathrm{Ar}$ at $500^{\circ} \mathrm{C}$ for $1 \mathrm{~h}$, then cooled to $40^{\circ} \mathrm{C}$ and saturated at this temperature with ammonia. After adsorption reached equilibrium, the sample was heated from $40^{\circ} \mathrm{C}$ to $500^{\circ} \mathrm{C}$ at a rate of $10^{\circ} \mathrm{C} / \mathrm{min}$ in flowing Ar. The $\mathrm{NH}_{3}$-TPD profile was recorded by a thermal conductivity detector (TCD).

Thermo-gravimetric analysis of the used-catalysts was performed in air atmosphere at a heating rate of $10^{\circ} \mathrm{C} / \mathrm{min}$ up to $900^{\circ} \mathrm{C}$ with SETSYS EVOLUTION TGA $16 / 18$.

\section{Results and Discussion}

\subsection{Activity and Stability}

The naphthalene methylation reaction is a surface heterogeneous catalytic reaction. Its activity is closely related to the accessible active surface sites and the pore structure of the catalyst [10]-[18]. We have studied the naphthalene methylation reaction on four kinds of PdO modified zeolitic materials: $\mathrm{H} \beta$, SAPO-11, HUSY and HZSM-5, with typical pore shapes. The topologies and pore structures of the four zeolites are listed in Table 1. As shown in Figure 1, the stability was greatly improved after modified by PdO comparing with the original zeolites [12]. The four modified zeolitic materials showed distinct naphthalene methylation conversion stability. Among the four catalysts, SAPO-11 showed the highest stability during the 9-hour on stream reaction. $\mathrm{H} \beta$ showed a high initial activity but deactivated immediately after a four-hour reaction. Both $\mathrm{H} \beta$ and USY were quickly deactivated possibly due to their tridimensional pore structures. The defusion barrier of such structures leads to the fast formation of carbonaceous deposits. It seems that the catalyst with a lower dimensional pore structure possesses a higher catalytic stability in a descending order of SAPO-11 $>$ ZSM-5 $>$ USY $\approx \beta$. The molecular sizes of the raw material naphthalene and the products such as alkylated naphthalene are comparable compared with zeolitic pore size. As a result, the reactants and products are more difficult to diffuse in the tridimensional pores than in the unidimensional pores. Since mass transfer in low-dimensional channels is much easier than in zeolites with more complicated multi-dimensional channels, we propose that the super-cage structure in $\beta$ and USY is most likely the main reason for the fast deactivation as a consequence of carbon deposition in these cages [4]. It has been reported that the 1-D pore structured zeolites are more resistant to deactivation arising from carbonaceous deposition [8] [19]. The relatively longer catalytic life and more excellent activity of SAPO-11 may therefore be attributed to its well-matched pore-size with the naphthalene molecule and its one-dimensional (1-D) non-intersecting elliptical pore channels [9]. In general, the superior durability of PdO/ SAPO-11 and PdO/ZSM-5 when compared to $\mathrm{PdO} / \beta$ and $\mathrm{PdO} / \mathrm{USY}$ suggests that low-dimensional pore structures benefit the methylation reaction. The stability observations further suggest that the naphthalene methylation is a shape-selective process.

\subsection{Selectivity of 2,6-DMN and $\sum 2,6-\mathrm{DMN}$}

The synthesis selectivity for 2,6-DMN of the four selected zeolitic modified materials within a 9 hour reaction are presented in Figure 2(a). The 2,6-DMN selectivity of these modified zeolites increases in the sequence of $\mathrm{USY}<\beta<$ ZSM-5 $<$ SAPO-11. SAPO-11 showed a selectivity of $28 \%$ to $2,6-\mathrm{DMN}$, which is higher than the selectivities of other three catalysts under much milder working pressure, i.e., atmospheric conditions. Furthermore, it can be seen from Figure 2(b) that the 2,6-DMN/2,7-DMN ratio of PdO modified SAPO-11 is much higher than that of others (about 1.5 for SAPO-11 and about 1.0 for other three modified catalysts). The exceptional high 2,6-DMN/2,7-DMN molar ratio implies higher purity and selectivity to 2,6-DMN than 2,7-DMN for SAPO-11 compared to the other zeolitic materials. As mentioned above, it is extremely hard to physically separate 2,6-DMN and 2,7-DMN since their boiling points only differ by $0.3^{\circ} \mathrm{C}$ [20]. On the other hand, as 2,6-DMN and 2,7-DMN can form eutectic crystals at a ratio of 0.73 , the high selectivity ratio makes the refining of 2,6-DMN by recrystallation feasible [6].

In addition to the targeted 2,6-DMN in the naphthalene methylation, the 1,5-DMN and 1,6-DMN products are 


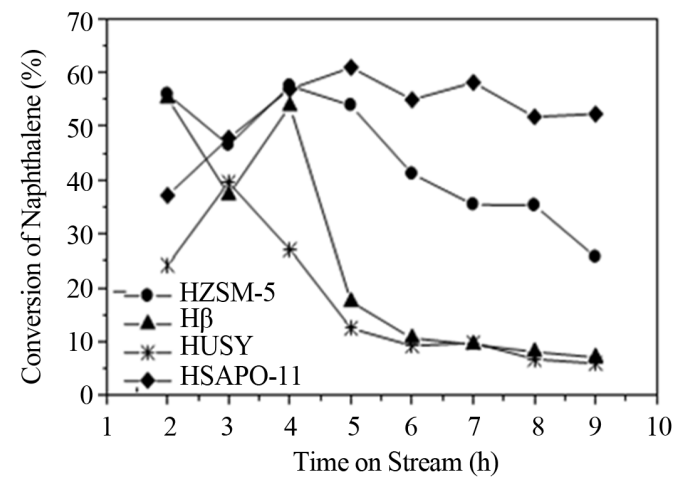

Figure 1. Naphthalene conversion for a selection of different porous materials.
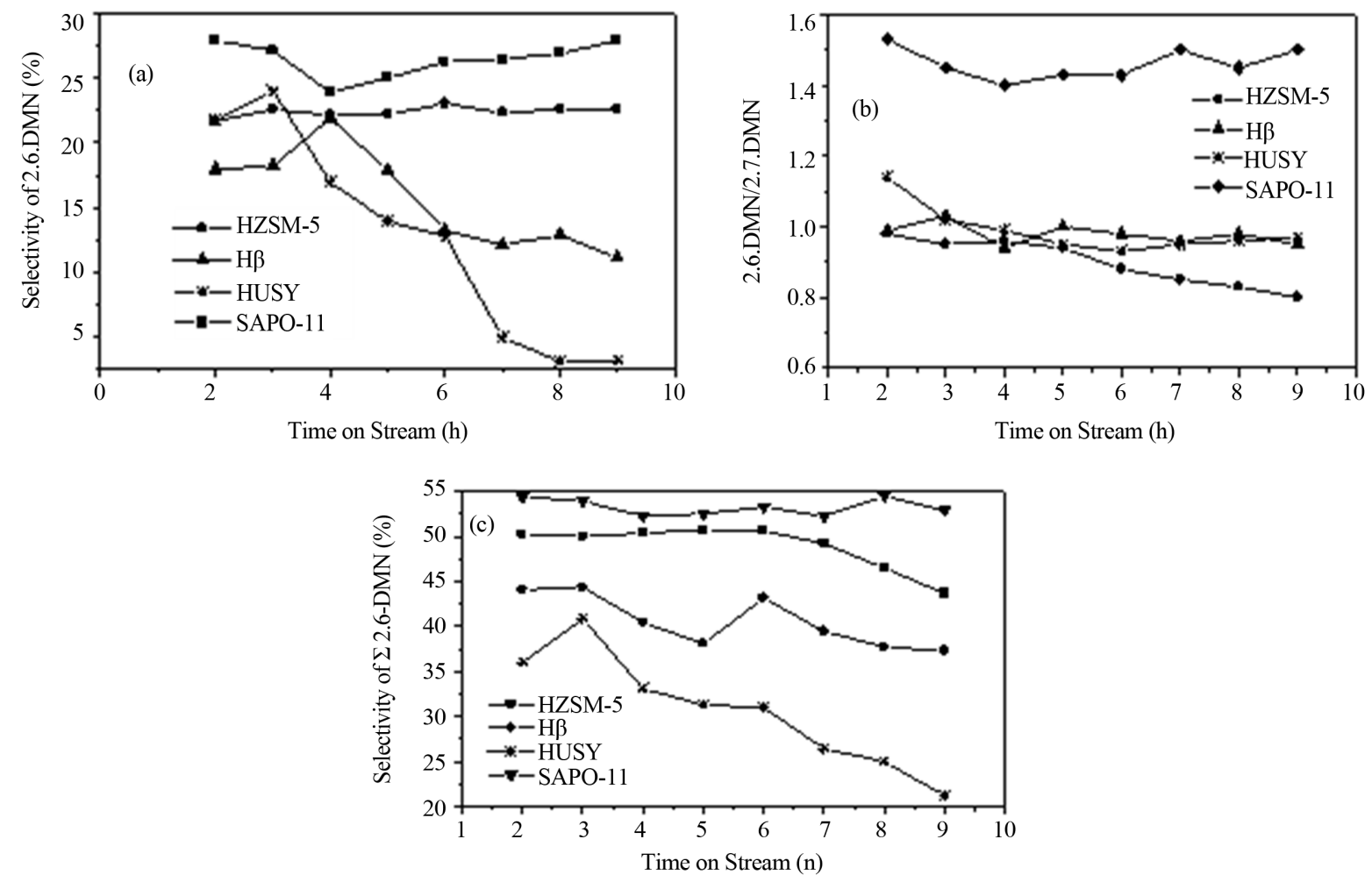

Figure 2. The selectivity of (a) 2,6-DMN, (b) 2,6-DMN/2,7-DMN molar ratio and (c) 22,6-DMN on different catalysts.

also considered as valuable components since they both can be easily transformed into 2,6-DMN by facile isomerization [21]. Therefore, it is sensible to assess the overall selectivity to 2,6-DMN (denoted as $\sum 2,6-\mathrm{DMN}$ ) on these catalysts by the sum of 2,6-, 1,6-, and 1,5-DMNs, which reveals the indirect selectivity of 2,6-DMN. As shown in Figure 2(c), modified SAPO-11 shows the highest selectivity for $\sum 2,6-\mathrm{DMN}$ with respect to the other three zeolitic materials.

In order to understand the selectivity to 2,6-DMN over the different catalysts, it is necessary to re-examine their structures and the molecular configuration of 2,6-DMN. As shown in Figure 3, according to the $a b$-initio calculation by $\mathrm{H}$. Hu [22], the elliptical configuration of 2,6-DMN is the most stable, with specific molecular dimension of $0.64 \mathrm{~nm} \times 0.28 \mathrm{~nm} \times 1.01 \mathrm{~nm}$. These dimensions are perfectly consistent with the elliptical 10-MR pore shape observed in SAPO-11 $(0.64 \mathrm{~nm} \times 0.39 \mathrm{~nm})$ [13]. The 2,7-DMN isomer, as shown in Figure 3, is clearly less adaptive to the linear channels of SAPO-11 due to its molecular conformation. By taking the pore 


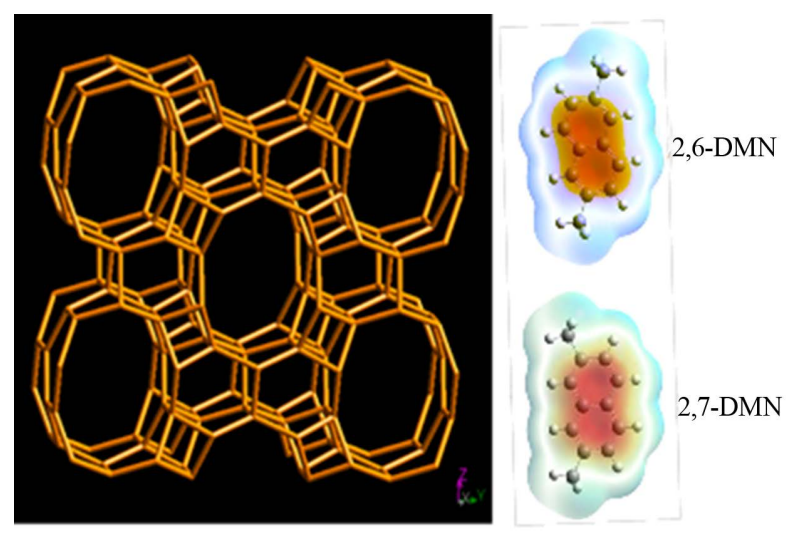

Figure 3. The pore structure of SAPO-11 (left) and the $a b$-initio molecular shape of the most stable configurations of 2,6DMN and 2,7-DMN by H. Hu (right).

shapes of SAPO-11 and molecular configuration of 2,6-DMN into account, it is reasonable to attribute the high selectivity of 2,6-DMN to a shape-selective effect of SAPO-11. This is consistent with the results observed for the other selected zeolite materials, which have either larger or smaller pore sizes (Table 1) and thus are not in favor of a high selectivity of 2,6-DMN due to the shape-selective reaction occurring in the zeolite channels. Though larger pores could promote the diffusion of reactants/products, and consequently the overall conversion, the excessive space within large channels is not in favor of a shape-selective reaction, particularly when there are several thermodynamically possible products with similar configurations. A suitable pore dimension can always facilitate the polyalkylation process and also discriminate among thermodynamically favorable isomers in the reaction [23].

\subsection{Effect of the Zeolites' Acidity}

Yang et al. investigated the relationship between the selectivity of naphthalene methylation on a series of zeolites with respect to their surface acidities, and concluded that the weak acid catalysts favor the formation of 2,6-DMN rather than its 2,7-DMN isomer as surface sites with stronger acidity are more resistant to coking [8]. The surface acidity of the selected zeolites before modification was tested through $\mathrm{NH}_{3}$-TPD with the results presented in Figure 4 (see reference [12]). The acidity strength of the selected zeolites is in the descending order of HUSY $>$ HZSM- $5>\mathrm{H} \beta>$ SAPO-11, which is not directly consistent with the observed selectivity, activity and stability orders of the zeolites. SAPO-11 has the weakest surface acidity but the highest activity, stability and selectivity, which suggests that surface acidity is important to restrain coking in methylation reaction but is not a dominant factor.

\subsection{The Accumulated Carbon on the Used Catalysts}

After the methylation of naphthalene proceeded for nine hours at the same condition, the used catalyst was collected for further characterizations. Thermo gravimetric analysis (TGA) curves of the four used catalysts (used $\mathrm{PdO} / \mathrm{ZSM}-5$, used $\mathrm{PdO} / \beta$, used $\mathrm{PdO} / \mathrm{USY}$ and used PdO/SAPO-11) are shown in Figure 5. There are two main weight loss stages for every TG curve. The first stage below $200^{\circ} \mathrm{C}$ is attributed to the removal of water physically adsorbed. The second one is between $400^{\circ} \mathrm{C}$ and $700^{\circ} \mathrm{C}$ which comes from the pyrolysis of carbonaceous deposits on the used catalysts. The used PdO/SAPO-11 has a total weight loss of ca. 3.5\% compared to a weight loss of ca. $7.1 \%$ for ZSM-5, $25.1 \%$ for $\beta$ and $17.8 \%$ for USY, respectively. It is obvious that used SAPO- 11 has the least amount of carbonaceous deposits among the four used zeolites after the reaction being carried out for the same time. It is not only because SAPO-11 has the relatively weaker acidity but mainly because of its suitable pore structure for the methylation of naphthalene to synthesize 2,6-DMN.

\section{Conclusion}

In summary, the selective synthesis of 2,6-DMN from naphthalene and methanol was investigated over a num- 


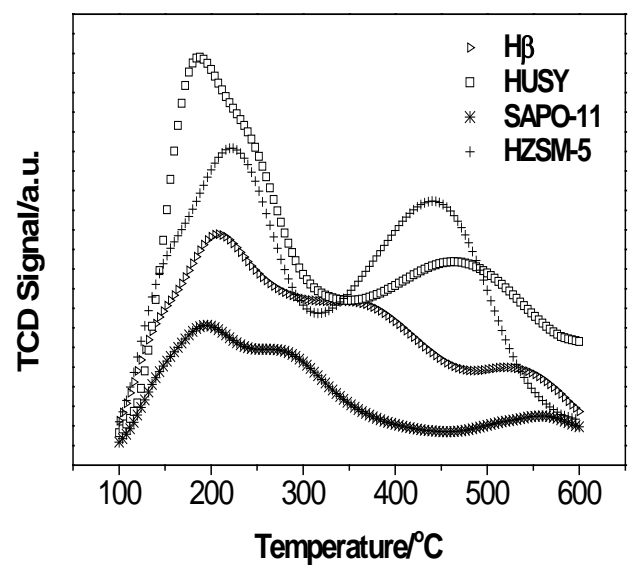

Figure 4. $\mathrm{NH}_{3}$-TPD profiles for the selected zeolite materials.

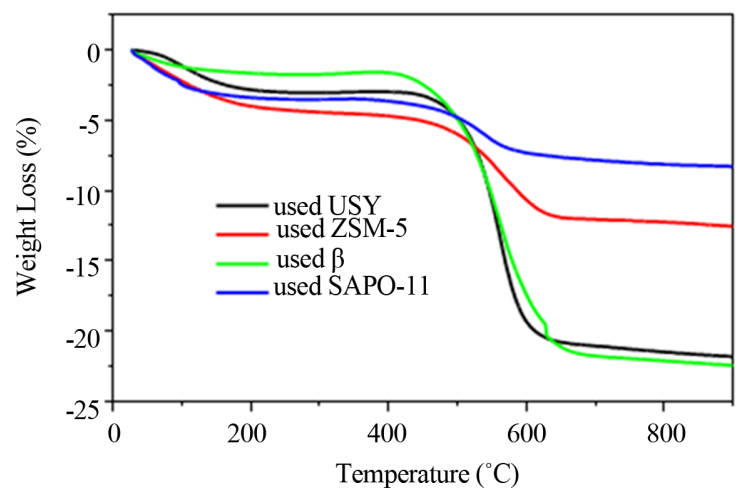

Figure 5. Thermogravimatric analysis curves for the used catalysts.

ber of typical microporous zeolite catalysts modified by PdO under ambient pressure. The stability was improved after modified by PdO. Furthermore, PdO/SAPO-11 was found to possess the highest 2,6-DMN selectivity, 2,6-DMN/2,7-DMN ratio and long catalyst lifetime. The outstanding catalytic performance of SAPO-11 arises as a result of its pore structure, while its surface acidity also plays an important role in the naphthalene methylation reaction. The high selectivity and remarkable stability of SAPO-11 suggest the potential for 2,6DMN production by methylation of the naphthalene and methanol. The modification of SAPO-11 by other metal oxides to further improve the selectivity of 2,6-DMN is under progress.

\section{Acknowledgements}

The authors are grateful to the Shanxi International Cooperation Project (2010081019) and Innovation Fund of ICC, CAS (ylsc5c1581).

\section{References}

[1] He, Z. and Zhu, L. (2001) Prepartion and Application of 2,6-Naphthalene Dicarboxylic Acid and Dimethyl-2, 6Naphthalene Dicarboxylate. Coke Chemical Industries, 94, 51-56.

[2] Chemical Market Reporter, 1999.

[3] Fraenkel, D., Cherniavsky, M., Ittah, B. and Levy, M. (1986) Shape-Selective Alkylation of Naphthalene and Methylnaphthalene with Methanol over H-ZSM-5 Zeolite Catalysts. Journal of Catalysis, 101, 273-283. http://dx.doi.org/10.1016/0021-9517(86)90254-X

[4] Pu, S. and Inui, T. (1996) Synthesis of 2,6-Dimethylnaphthalene by Methylation of Methylnaphthalene on Various 
Medium and Large-Pore Zoelite Catalysts. Applied Catalysis A, 146, 305-316. http://dx.doi.org/10.1016/S0926-860X(96)00182-2

[5] Komatsu, T., Araki, Y. and Namba, S. (1994) Selective Formation of 2,6-Dimethylnaphthalene from 2-Methylnaphthalene on ZSM-5 and Metallosilicates with MFI Structure. Studies in Surface Science and Catalysis, 84, 1821-1828. http://dx.doi.org/10.1016/S0167-2991(08)63737-4

[6] Millini, R., Frigerio, F., Bellussi, G., Pazzuconi, G., Perego, C., Pollesel, P. and Romano, U. (2003) A Priori Selection of Shape-Selective Zeolite Catalysts for the Synthesis of 2, 6-Dimethylnaphthalene. Journal of Catalysis, 217, 298-312.

[7] Park, J., Wang, J., Hong, S.I. and Lee, C. (2005) Effect of Dealumination of Zeolite Catalysts on Methylation of 2-Methylnaphthalene in a High-Pressure Fixed-Bed Flow Reactor. Applied Catalysis A, 292, 68-75. http://dx.doi.org/10.1016/j.apcata.2005.05.039

[8] Bai, X., Sun, K., Wu, W., Yan, P. and Yang, J. (2009) Methylation of Naphthalene to Prepare 2, 6-Dimethylnaphthalene over Acid-Dealuminated HZSM-12 Zeolites. Journal of Molecular Catalysis A, 314, 81-87. http://dx.doi.org/10.1016/j.molcata.2009.08.020

[9] Martens, J., Grobet, P. and Jacobs, P. (1990) Catalytic Activity and Si, Al, P Ordering in Microporous Silicoaluminophosphates of the SAPO-5, SAPO-11, and SAPO-37 Type. Journal of Catalysis, 126, 299-305. http://dx.doi.org/10.1016/0021-9517(90)90068-U

[10] Hu, Y., Wang, X., Guo, X., Xu, P. and Li, S. (2004) Hydroisomerization of n-Octane over Pt/SAPO-41 Catalyst. Chinese Journal of Catalysis, 86, 45-51.

[11] Wang, L., Guo, C., Huang, X. and Li, Q. (2002) Synthesis of High Si-Containing SAPO-11 by Post-Si Method. Chemistry Letters, 31, 1012-1013. http://dx.doi.org/10.1246/cl.2002.1012

[12] Wen, J., Wang, G., Zhang, Y. and Qiu, Z. (2010) Shape-Selective Catalytic Methylation of Naphthalene with Methanol over SAPO-11 Molecular Sieve Catalyst. Petrochemical Technology, 39, 487-491.

[13] Campelo, J.M., Lafont, F. and Marinas, J.M. (1997) Comparison of the Activity and Selectivity of Pt/SAPO-5 and Pt/SAPO-11 in n-Hexane and n-Heptane Hydroconversion. Applied Catalysis A: General, 152, 53-62. http://dx.doi.org/10.1016/S0926-860X(96)00347-X

[14] Newsam, J.M., Treacy, M.M.J., Koetsier, W.T. and de Gruyter, C.B. (1988) Structural Characterization of Zeolite Beta. Proceedings of the Royal Society (London) A, 420, 375-405.

[15] Hriljac, J.A., Eddy, M.M., Cheetham, A.K., Donohue, J.A. and Ray, G.J. (1993) Powder Neutron-Diffraction and SI-29 Mas NMR-Studies of Siliceous Zeolite-Y. Journal of Solid State Chemistry, 106, 66-72. http://dx.doi.org/10.1006/jssc.1993.1265

[16] Kokotailo, G.T., Lawton, S.L., Olson, D.H. and Meier, W.M. (1978) Structure of Synthetic Zeolite ZSM-5. Nature, 272, 437-438. http://dx.doi.org/10.1038/272437a0

[17] van Koningsveld, H. and Jansen, J.C. (1996) Single Crystal Structure Analysis of Zeolite H-ZSM-5 Loaded with Naphthalene. Microporous Materials, 6, 159-167. http://dx.doi.org/10.1016/0927-6513(95)00097-6

[18] Xie, Y. and Tang, Y. (1990) Spontaneous Monolayer Dispersion of Oxides and Salts onto Surfaces of Supports: Applications to Heterogeneous Catalysis. Advances in Catalysis, 37, 1-43. http://dx.doi.org/10.1016/S0360-0564(08)60362-4

[19] Pazzucconi, G., Perego, C., Millini, R. and Frigerio, F. (2000) Process for the Preparation of 2,6-Dimethylnaphthalene Using a MTW Zeolitic Catalyst. US 6147270.

[20] Takagawa, M. and Shigematsu, R. (2000) Process for Producing Highly Pure 2,6-Dimethylnaphthalene. US Pat Appl, US 6072098.

[21] Sikkenga, D., Zaenger, I. and Williams, G. (1991) Preparation of a Dimethylnaphthalene. US Pat Appl, US 5012024.

[22] Fang, Y. and Hu, H. (2006) Shape-Selectivity in 2, 6-Dimethylnaphthalene Synthesis over ZSM-5: Computational Analysis Using Density Functional Theory. Catalysis Communications, 7, 264-267. http://dx.doi.org/10.1016/j.catcom.2005.11.006

[23] Pazzuconi, G., Terzoni, G., Perego, C. and Bellussi, G. (2001) 25-O-03-Selective Alkylation of Naphthalene to 2,6Dimethylnaphthalene Catalyzed by MTW Zeolite. Studies in Surface Science and Catalysis, 135, 4071-4078. http://dx.doi.org/10.1016/S0167-2991(01)81251-9 